Article

\title{
Bodybuilding and Fitness Doping in Transition. Historical Transformations and Contemporary Challenges
}

\author{
Jesper Andreasson 1,*(i) and Thomas Johansson 2 (D) \\ 1 Department of Sport Science, Linnaeus University, 39182 Kalmar, Sweden \\ 2 Department of Education, Learning and Communication, University of Gothenburg, \\ 40530 Gothenburg, Sweden; thomas.johansson.2@gu.se \\ * Correspondence: jesper.andreasson@lnu.se
}

Received: 16 January 2019; Accepted: 27 February 2019; Published: 4 March 2019

check for updates

\begin{abstract}
This article describes and analyses the historical development of gym and fitness culture in general and doping use in this context in particular. Theoretically, the paper utilises the concept of subculture and explores how a subcultural response can be used analytically in relation to processes of cultural normalisation as well as marginalisation. The focus is on historical and symbolic negotiations that have occurred over time, between perceived expressions of extreme body cultures and sociocultural transformations in society - with a perspective on fitness doping in public discourse. Several distinct phases in the history of fitness doping are identified. First, there is an introductory phase in the mid-1950s, in which there is an optimism connected to modernity and thoughts about scientifically-engineered bodies. Secondly, in the 1960s and 70s, a distinct bodybuilding subculture is developed, cultivating previously unseen muscular male bodies. Thirdly, there is a critical phase in the 1980s and 90s, where drugs gradually become morally objectionable. The fourth phase, the fitness revolution, can be seen as a transformational phase in gym culture. The massive bodybuilding body is replaced with the well-defined and moderately muscular fitness body, but at the same time there are strong commercialised values which contribute to the development of a new doping market. Finally, it is possible to speculate on the development of a fifth phase, in which fitness doping is increasingly being filtered into mainstream gym and fitness culture, influencing the fitness doping demography.
\end{abstract}

Keywords: fitness doping; gym culture; extreme bodies; gender; bodybuilding

\section{Introduction}

With promises of new technologies, and the use of biochemical resources to boost performance and muscle mass, doping historically has been (and still is) intertwined with the development of modern organised sport. The history of doping is, thus, also a history of modernity and the plastic and changeable body. Through hegemonic ideas/ideals about performing bodies different sports have been successively modernised since the mid-1800s (Dimeo 2007), and within this modernisation process we also find the use of performance and image-enhancing drugs (PIED). For example, in the 1930s different kinds of drugs were used to combat fatigue and to increase sport performance. This was largely done in a non-judgemental fashion, especially in comparison with contemporary perspectives on doping in public discourse. Anabolic androgenic steroids (AAS) were also widely used among soviet weightlifters and American bodybuilders (among others) in the 1950s (Dimeo 2007; see also Connolly 2015). Consequently, PIED use was to some extent understood as part of a medical and scientific approach to the performing, muscular and competent (male) body (Holt et al. 2009).

The use of AAS and, more broadly, prohibited doping substances in a sport context has been debated for decades. Yet, studies indicate that the main reasons for people starting to use these 
drugs are connected to muscle building and image-enhancing purposes, and as such closely related to the development of gym and fitness culture (Evans-Brown et al. 2012). In relation to the global development and expansion of gym and fitness culture, the use of PIED amongst gym members has been reported in a number of countries in Europe (Christiansen 2018; Hoff 2013; Kimergård 2015), in North America (Pope et al. 2014), in Brazil (Santos et al. 2011), the United Arab Emirates (Al-Falasi et al. 2008) and Iran (Allahverdipour et al. 2012) to name a few. Thus, fitness doping seemingly presents a challenge to public health on a global scale. Although recognised in research, the worldwide trade in, and use of, doping substances, in general and in contrast to the continual refinement of anti-doping organisations and work, has continued to increase over time (Antonopoulos and Hall 2016). Furthermore, despite the predominant role played by the Internet concerning the distribution of PIEDs, little is known about the online availability and global distribution of doping products in contemporary societies (Pineau et al. 2016).

This article describes and analyses the historical development of doping use in the context of bodybuilding and fitness culture. The focus is on historical and symbolic negotiations that have occurred over time, between perceived expressions of extreme body cultures and sociocultural transformations in society-with a perspective on fitness doping in public discourse. The paper is to be regarded mainly as a literature review, based on a rich variety of studies describing and analysing bodybuilding and fitness culture in general and fitness doping in particular, but there is also an ambition to analyse historical transformations of bodybuilding and fitness doping and to develop a theoretical understanding of this phenomenon. Consequently, important and decisive historical developments within gym and fitness culture will be identified and analysed with an ambition: (a) to present the general background to fitness doping and (b) develop an analytically informed approach to how this practice can be conceptualised using a sociocultural and sociologically theoretical framework, and (c) point towards possible future developments.

\section{Analytical Point of Departure}

An important focus in the paper is the relationship between, on the one hand, the more subcultural phenomenon of bodybuilding, doping and extreme bodies, and on the other hand a more general approach to the body found in gym and fitness culture. What we are trying to elaborate on is the relationship between a more 'deviant' and criminal activity and lifestyle, and a common and normalised practice of using different means and methods to promote a specific body ideal. We have chosen to elaborate on the concept of subculture, and its relation to what can be considered as hegemonic culture, that is, the sociocultural context and understanding of everyday life which is embraced by most people in society. We are, of course, aware that this distinction is hard to draw, and our intention is not to define and once and for all decide where a line should be drawn, but rather to use this frame as a point of entry for the paper.

In theories of subcultures, we often find a more or less clear distinction between subculture and mainstream or common culture. There is, of course, a varying, complex relationship between what is 'sub' and what is dominant or hegemonic (Johansson and Herz 2019). Subcultures are frequently striking, but there is also a strong affinity between everyday culture and different subcultures (Baker et al. 2015). The visibility, distinctness, and desire expressed in subcultural communities serve to recruit people to these kinds of subgroups. The perspectives on subcultures have also varied. According to Hebdige (1979), for example, subcultures are implacably incorporated into and consumed by mainstream culture. At the same time, and in contrast, Hodkinson (2002) has argued that there is often a high level of distinctiveness, stability, and durability, in the sense of collective identity, fostered within subcultures. Thus, what we are studying here is a relationship between common and general sociocultural patterns in society and more specific and distinct sociocultural patterns. Defining mainstream or common culture is, of course, almost impossible. In a similar vein, what is regarded as subcultural varies greatly. Given this, we must be satisfied with trying to grapple with and understand the ongoing and changing relationship between more general versus more specific sociocultural patterns in society. 
A closer look at specific subcultures provides a clearer picture of the importance of subcultures in relation to changing subjectivities (Johansson et al. 2017). In particular, we can see how subcultures are intimately interwoven with and tied in with societal and cultural transformation. Bodybuilding, for example, has been successively transformed into fitness since the 1970s. To this end it has gradually moved in the direction of becoming mainstream. The core values of the hard-bodybuilding-body, focused on muscle training, health and asceticism, are for example highly present in the contemporary fitness culture, as well as in more common and dominant sociocultural patterns in many Western countries. What is interesting here is the process through which common culture gradually incorporates certain lifestyle attributes and values of the subculture of bodybuilding. Body techniques, discipline, and knowledge about how to transform the body are being modified, marketed, and commercialised. Yet, certain bodies are still labelled as being 'too' extreme-that is, connected to unhealthy lifestyles, drugs, and narcissism - and are thus being marginalised from the more public domains of fitness culture. The intricate interplay between the subculture and the processes of mainstreaming is a central mechanism in contemporary fitness culture. Some aspects of body ideals and lifestyles are incorporated into more general cultural trends, while some other aspects are not.

If we explore the relationship between subcultures and the mainstreaming of certain values, opinions, and practices, it becomes apparent that certain subcultural values and sentiments gradually and over time tend to become normalised, accepted, and routinised ways of relating to, for example, the body, health, drugs, politics, and societal values. Subcultural expressions and styles become significant and worth studying when they affect the balance between what is subcultural and what is 'common'. This is also a part of the fascination and desire involved in the constant transformation and interplay between subcultures and society, between 'the extreme' and 'the normal', the healthy and unhealthy, and the criminal and legal.

Starting from this conceptual discussion we will in the remainder of this paper describe the general history of fitness doping and, identify a number of historically significant transformations concerning how drug-using practices have been understood and negotiated in relation to societal and cultural developments.

\section{The Pre-History of Bodybuilding, Gym Culture and Doping}

Just as the alchemist has sought the magic formula for making gold, there are examples throughout history of people searching for a 'magic potion' to give them a competitive edge, and a short cut to the goals they have set themselves. The use of PIED can also be traced back to values and ways of approaching the physical competent body and hegemonic body ideals in, for example, ancient Greece (Verroken 2006). A more contemporary period in the history of fitness doping relates to the early 1900s and what has been called the development of physical culture.

Located mainly in the United States, the development of physical culture brought new techniques to form and develop a strong, muscular and masculine-connoted body (Budd 1997). Influenced by the Swedish, Danish and German gymnastic movements, scientists in the US, and internationally, gradually turned their focus and interest towards physical education, and methods for improving health and strength (Andreasson and Johansson 2014). At this time, physical supporters and the medical establishment did not encourage excessive muscular development. The advice was to concentrate on gymnastics and hygienic moderation, rather than to build muscles (Vertinsky 1999). When strongman Eugen Sandow, generally referred to as one of the founding fathers of bodybuilding, arrived in America in 1893 he was initially, and quickly, criticised and laughed at. Sensing the attitudes and the fashion of the time, Sandow did not market himself as the world's strongest man, but as the world's most developed and/or perfect man (Budd 1997). The medical profession was even more critical towards Bernarr MacFadden, the father of physical culture, and called him a narcissist. The members of the respectable medical profession saw MacFadden as an expression of a subversion of respectability, and also as a threat to the 'natural' boundaries between masculinity and femininity. 
The status of muscular bodies gradually changed, however. Early bodybuilding competitions in the 1930s and 40s were meant as public demonstrations of what bodybuilding could do to reverse the corrosive effects of modern civilisation (Liokaftos 2018). Emphasis was initially put on displaying the 'natural body'. Notions of ease, grace and naturalness were central to the participants' success as models. Gradually, classical ideals of Apollonian perfection resonating with ideals from ancient Greece were eroded and replaced by tanned mahogany bodies formed on the Californian beaches. In the late 1950s and 1960s PIEDs were also introduced in bodybuilding. At this time, the doctors and the medical profession were not critical towards muscular bodies. On the contrary, there was a growing fascination with the technological advances. In contrast to the medical profession's scepticism of muscular male bodies at the end of the 19th century, muscular male bodies were now regarded as a sign of progress and a successful scientifically-led control of the body and its growth.

At the 1954 World Weightlifting Championships in Vienna, Austria, an American doctor, John B. Ziegler, observed young Russian athletes using testosterone (Kremenik et al. 2006). He went home and produced a synthetic drug, based on testosterone. The drug, Dianabol, became a great success. In the 1960s, many bodybuilders had t-shirts saying: DIANABOL, BREAKFAST OF CHAMPIONS. To this end the early history of drug use in a bodybuilding context and sport doping shared a common pre-history. As suggested by Hunt et al. (2014) this history can also be placed within a framework of the Cold War and the different approaches to doping found during this time in, for example, east Germany and the USA (see also Dimeo 2006).

In 1957 the American Medical Association raised concerns about amphetamine use in different sports. According to Dimeo (2007) this period, the mid-1950s, saw the birth of the anti-doping movement, which has since developed into the World Anti-Doping Agency (WADA) which today works to protect athletes' health and ensure the notion of fair-play by detecting evidence of doping (Gleaves and Hunt 2015). According to Rosen (2008), the epicentre of steroid use was to be found among weightlifters at the legendary New York Barbell Club. The use of steroids rapidly spread to other sports as well as within the context of gym and fitness culture. In 1967, however, the Olympic committee outlawed PIEDs. The long-fought war against drugs started at this time, although stigmatisation processes associated with drug use were quite rudimentary in the beginning. In conclusion, the first historical phase of PIED use in the context of gym and fitness culture can be situated in parallel with and occurred in 'alliance' with modern society and sport. This period, which roughly stretches from the turn of the 20th century up to the 1960s, is characterised by optimism, scientific explorations, modernity, and also by a naïve understanding of the role of drugs in bodybuilding, as well as in sport. This was about to gradually change during a second phase.

\section{The Sculpted and Doped Body}

One central melting pot in the development of bodybuilding, and gym and fitness culture is found on the US West Coast. In the late 1930s and 40s a stretch of beach in Santa Monica, Muscle Beach, became a defining location for bodybuilding culture and lifestyles (Locks and Richardson 2012). Here, the beachfront soon became a public space where enthusiasts in the 1950s could gaze on the bodies of icons, such as Steve Reeves, among others. Reeves was known for his exceptional muscular definition and aesthetic appeal. The idealisations that made Reeves famous gradually came to change, however. In the early 60s, when Muscle Beach was 'moved' down the coast to what was thought to be a better location, in Venice Beach, a starting point of cultural transformation was initiated.

First, bodybuilders started to appear much more defined because of the introduction of diuretics that rid the body of excess water fluid, revealing far greater levels of muscularity and definition. Second, if one looks at bodybuilding magazines from this era, the physiques on display quite abruptly changed with an even greater impetus on mass than had been seen before. [...] The reason for this change was partly due to more effective exercise and better diet, but significantly to the emergence of anabolic steroids, a factor that irreparably cut off the sport from its classical 
roots and would function as the primary armature of a new American Classicism which made Reeves only a nostalgic ideal. (Locks and Richardson 2012, p. 11)

In the 1970s gym culture and the culture of bodybuilding blossomed. From being perceived more or less as a slightly purposeless, masculine, homosocial and subcultural preoccupation, bodybuilding was reborn, and the famous Gold's Gym in Venice Beach gradually developed from a small gym into a global franchise and cultural hub for bodybuilding. One driving force in this development was the documentary movie Pumping Iron (Gaines and Butler 1974), in which bodybuilding icons such as Arnold Schwarzenegger, Lou Ferrigno, Franco Columbo, and Frank Zane, and others, were followed preparing for the $1975 \mathrm{Mr}$. Olympia and Mr. Universe competitions.

In the wake of Schwarzenegger's success, it became more or less the norm in the US, as well as elsewhere, to work out and build muscles, at least among men. The health club industry also developed as part of a larger health movement, and this could be seen in the many companies at this time that were keen to offer their employees facilities and opportunities for physical exercise, in order to reduce the risk of heart attacks and other coronary diseases (McKenzie 2013). Working out became part of the urban, middle-class single lifestyle (Luciano 2001). Parallel with the development in bodybuilding we also have the fitness boom through which Jane Fonda and others developed not only a specific form of dance and gymnastics, called "workout", but also ideals of individualized and fit bodies. Although, at the time, partly separated cultural spheres of fit bodies, the body of Schwarzenegger and bodybuilding functioned as a nexus in this development. He embodied the American dream, an ethos saying that anything is possible as long as you put your mind to it. But while Schwarzenegger contributed greatly in making weightlifting a more common form of exercise for those not normally frequenting a gym, he simultaneously contributed to making bodybuilding more extreme and subcultural in terms of bodily development, size and vascularity.

Taking ideals of bodily perfection to a 'freakish' shock-value extreme, Schwarzenegger and bodybuilding in the 1970s were also entering an era of steroids. Even though experimental use of synthesised teststerone had already occurred at a number of gyms on the US West Coast in the 1950s (Yesalis and Bahrke 2007), it was during the 1970s that new types of drugs evolved into customised products with far less side-effects. Thus, whereas the use of PIEDs in the context of sport at this time encountered strong condemnations and preventative measures, the use was largely seen as unproblematic among bodybuilders and in gym and fitness culture-for example, in his revealing second autobiography Total Recall: My Unbelievably True Life Story, Schwarzenegger and Petre (2012) explained his outlook, stating that he has few regrets regarding steroids as they were something that were widely available on the market and were used under doctors' supervision.

The 1970s was a time of experimentation and the legislation against (fitness) doping was still at a very rudimentary level. Using, for example, steroids outside the sphere of organised sport was not only legal, but also somewhat accepted, not least in a bodybuilding context, internationally. Thus, firstly this development and perspective on PIED needs to be understood in relation to the specificity of the time in focus, and the liberal approach to experimentation in drug-taking in general, prominent in the $60 \mathrm{~s}$ and 70s. Secondly, as touched upon by Schwarzenegger, it is also possible to talk about a 'pharmacological revolution' through which pharmaceutical companies increasingly started to search for and develop more potent and less toxic drugs, which were able to alter biochemical, physiological and psychological functions in the body (Verroken 2006). Not surprisingly, bodybuilders, as well as athletes within competitive sport, saw great possibilities to utilise these chemical agents in order to push or exceed their limits, aiming to create something new and transgress their physicality.

\section{Female Bodybuilders—Crossing the Boundaries}

Although weightlifting and bodybuilding started much earlier, female bodybuilding was mainly set up in the late 1970s (Fair 1999). Initially there were only a few women lifting weights, and those who did entered competitions that were more beauty contests than bodybuilding events (Klein 1993). In this process male ideologues controlling bodybuilding did not particularly encourage women to 
become bodybuilders. Gradually, however, during the 1980s and 90s highly muscular and defined female bodies gained recognition both within bodybuilding and partly in public discourse. They were getting access to and, gradually, acceptance in, the more respected circuits and gyms, and competitors such as Debbi Muggli, Lenda Murray, Iris Kyle and Bev Francis could be seen posing with their massive and highly muscular bodies. The film Pumping Iron II (1985), in which four female bodybuilders are followed when preparing for the Caesar's Palace World Cup Championship, can also be understood as part of this breakthrough.

Women thus successively entered into the subculture of male bodybuilding, which signalled the start of a transformation of the whole idea of physical culture. Consequently, bodybuilding as a gendered practice was broadened (Andreasson and Johansson 2014). Interestingly, this development of the sport, was also parallel to a growing interest among researchers in body and gender studies in general, and to the development of feminist perspectives and theory in particular. Scholars, such as Butler (1990,1993), and Haraway (1990) among others, fuelled the intellectual discussion and problematisation of gender and gendered bodies through their contributions. People started to talk about ways of stretching/exceeding the limits of the human body in different ways, and the doing of gender. In the 1990s scholars also turned their interest towards female bodybuilders, as they were thought to represent something unique, something subversive, transgressional, and a vibrant challenge of hegemonic masculinity (Connell 1995). The imagery of female bodybuilding was, however, not unambiguous.

Despite increased empowerment, the prominent theme of female bodybuilders' experience is one of contradiction, often leading to attempts to "balance" popular notions of femininity and muscularity. Critical feminists, postmodernists, and sport sociologists describe how female bodybuilders balance contradictory demands of muscular development versus expectations of normative femininity. These include regulating muscular size to avoid being labeled as "too big," "mannish," or lesbian (...) using body technologies such as breast enlargements, plastic surgeries, and feminising hairstyles, outfits, and accessories to counteract the "masculinising" effects of steroid use or loss of breast tissue. (McGrath and Chananie-Hill 2009, p. 237)

Punitive sanctions and explicit ideology around women who are thought to violate normative gender configurations in society, used to set up perimeters around women's behaviour, echo through the cultural history of gym and fitness culture. Female bodybuilding has often been considered a threat to the 'natural' gender order in public discourse, and discussions about female athletes have tended to focus on boundaries between male/female, natural/unnatural, and about potential gender transgression with or without the use of PIED. To this end, female bodybuilders historically have found themselves trapped in conflicting discourses that pit sexual difference against an ethic of a universal, transcendent, and undifferentiated body culture (Lindsay 1996; Richardson 2008; Roussel et al. 2010). Wesely (2001) has also argued that PIED use and other body technologies should be viewed as a continuum between 'natural' and 'unnatural' bodies, emphasising that the gender line between men and women is negotiable and changes over time and across contexts. In a similar vein, the status of the huge muscular body has changed over the years in focus, and although gendered understandings of PIED use have to some extent prevailed, the rise of female bodybuilding as a phenomenon has signalled a movement towards gym and fitness as a mass leisure activity. At the same time frequent reports on PIED use and the obsessional traits of bodybuilders have served as a counterweight in this development (Bunsell 2013).

In conclusion, during the second historical phase, stretching from the 70s into the early 90s, gym and fitness culture widened in terms of gender, among other things. During the golden age of bodybuilding, which followed in the wake of Schwarzenegger's success, women became gradually (to some extent) integrated into the previously more or less exclusive male culture and ideology. Highly muscular female and male bodies, achieved with the help of PIEDs, became a topic of discussion not only in bodybuilding circuits but also in public discourse and within academia. Furthermore, being 
legal in most countries, the use of steroids, was more or less seen as part of the competitive culture of bodybuilding, which at this time profoundly differed from perspectives on doping in the context of organised sport. Entering the 1990s, however, new winds were blowing.

\section{Confessions and Crises in Bodybuilding}

At the end of the 1980s and beginning of the 1990s bodybuilding gradually started to get a bad reputation, entering into the third phase of the historical development of gym and fitness culture in general and doping practices in this cultural context in particular. Klein (1993) now classic study on competitive bodybuilders on the American West Coast touches upon this process and discusses it in terms of a change of public perspective as well as transforming subcultural understandings of the self within bodybuilding. Viewing themselves as nutritional and kinesiological experts, the bodybuilders of the 80s in Klein's study are positioned at the top of the food chain in a developing culture of vanity, saluting muscles, vitality, sexuality, control, health and prowess. As proponents of this healthy lifestyle and culture (which included drug-using practices), Klein's participating bodybuilders could offer their services, and counsel and train others in the art of bodybuilding, for a fee. Ironically and in direct contrast to the public declaration of fitness and health, however, the previous acceptance of PIED use among bodybuilders started to bring about bad publicity. Paralleling the growth and expansion of gym and fitness culture and the increasing popularity of muscle-building practices, there was thus a recognition and construction of a darker side of bodybuilding. (Luciano 2001). Psychiatrists started to describe a new category of young patients, obsessively preoccupied with their bodies and muscularity. In 1988, the world was also shocked by the news that sprinter Ben Johnson had used steroids. Johnson was not the first Canadian athlete to test positive for performance-enhancing substances. However, the hype surrounding his gold-medal win, and Johnson's position in the global sport world, shocked his supporters and the Canadian audience. The awareness of the widespread use of drugs by athletes, and ordinary young men too, changed things. Drugs became associated with shame and losing one's reputation as a sportsman.

Consequently, through this process, and through different autobiographies, such as Muscle: Confessions of an Unlikely Bodybuilder (Fussell 1991), by Sam Fussell, the subculture of bodybuilding was thoroughly reviewed and scrutinised.

In September 1984, Fussell read Arnold Schwarzenegger's original autobiography: The Education of a Bodybuilder, and decided to get involved in bodybuilding. He soon felt good, and he admired the simplicity and the discipline. Having felt a deep anxiety before, he felt relaxed and enjoyed the routines and the hard training schedules. When arriving in California and Gold's Gym, he also started to use steroids. One man at the gym, Vinnie, introduced him to the drugs. Fussell writes: 'That very day, Vinnie began my education as a bodybuilder and instructed me on the merits of performance-enhancing drugs' (p. 118). Although Fussell was aware of the possible side-effects of the drugs, he began to use the needles.

And there were other little problems from the drugs, the sheet said, problems like premature baldness, lowered sperm count, increased body hair, rectal bleeding, dizzy spells, thyroid and liver and kidney malfunction, gallstones, cancer, gastrointestinal upset, hepatitis, raised levels of aggression ... (p. 121)

Fussell told himself that he made a bargain with the devil, in exchange for transcending his body and creating something extraordinary. Although his training gave results, he started to feel alienated from himself, his parents and society. Looking at himself in the mirror, he was no longer sure that bodybuilding was the right way to go. Gradually he discovered that he had to leave the sport, and to continue his life, following another path. Leaving the bodybuilding lifestyle, however, was not easy.

Despite all I knew, leaving iron wasn't that simple, of course. No iron veteran after all, just walks away. Without the buttresses and corbels, the brackets and bolstering devices of muscles, bodybuilders feel they'd collapse quicker than a house of cards. It's no wonder the 
rate of recidivism is astronomically high, and all my gym friends assumed that I'd be no exception. (p. 250)

Writing the book was very much an attempt at self-exile from bodybuilding. Fussell understood that he would not be welcomed by his old friends and at the gym anymore. After releasing the book, he was constantly on tour, talking about the book and his life as a former bodybuilder.

Fussel's book helped to create ripples on the water, presenting a strong critique on American macho. In a similar vein, Klein (1993) study on American West Coast bodybuilders helped to reveal a hyper-masculine subculture coloured by homophobia and misogyny, but paradoxically also homosexual hustling. In general, the muscle-building practices at this time-through the use of steroids-were thus understood as a means to compensate a vulnerable and insecure masculinity. Consequently, in the third historical phase of fitness doping we find complex movements in which a doped bodybuilding masculinity, and bodybuilding culture, is questioned, at the same time as women continue to gradually enter and gain a position in this culture. The issue of health becomes paramount, as do the discussions on side-effects following PIED use among men and women.

\section{The Fitness Revolution-Cleaning Up the Mess}

In the late 1990s and especially when moving forward to the first two decades of the 21st century, there was an explosion of fitness franchises and an increasing number of people were attracted to fitness. Entering the fourth phase of the historical development of gym culture and fitness doping, the subculture of bodybuilding was gradually disconnected from a more general trend of fitness gyms and from a conception of the gym as a place for everyone and a mass leisure activity with strong connotations to health and sound lifestyles (Smith Maguire 2008; Sassatelli 2010). The effects of drug use in bodybuilding were thoroughly investigated and there were more checks in the gyms. A Danish study, for example, showed that fitness franchises such as SATS and Fitness World, used drug tests to maintain a good reputation and to remove bodybuilders from their gyms (Mogensen 2011).

The fitness revolution in the 1990s can be seen as a reaction towards the falling star of bodybuilders and an attempt to sanitise the sport. Frequent reports on drug use, and anabolic steroids, combined with the obsessional characteristics of bodybuilding, led to a diminishing interest in bodybuilding. The cultural and gradual separation between bodybuilding and fitness does not mean that these phenomena become two different activities and lifestyles however. These conceptions of exercise and lifestyle are partly disconnected from each other and partly increasingly dependent on each other. Fitness has become the overall concept used when referring to health clubs and fitness franchises, and has thereby turned into a popular movement, but not one comparable to the old 20th-century movements, often connected to national sentiment, but instead highly individualised and personal (Andreasson and Johansson 2014).

As regards female bodybuilding, which gained increasing recognition during the 80s and early 90 s, the scenario has changed since the turn of this century. On an organisational level the governing body of bodybuilding and fitness, the International Federation of Bodybuilding and Fitness (IFBB), increasingly started to insist that women must maintain their 'female form' and muscle definition. In line with this, the concept and discipline of Women's Fitness, was introduced in 1996, paving the way for a 'less muscular and aesthetically pleasing physique' and ideal for female bodybuilders (IFBB 2018). Later disciplines such as Women Bodyfitness and Women's Bikini-Fitness were also added to further accentuate the marginalisation of female bodybuilding. This is clearly exemplified with the fact that the Ms. Olympia contest for the biggest women was dropped, as part of the focus on new categories.

In many ways this development can be understood as a means through which organisers and central stakeholders within bodybuilding have aimed to adjust the development of the sport, adapting it to what is considered to be a more traditional gender order. Of course, as the female bodybuilding bodies of the 1990s steadily grew in mass and vascularity, discussions on doping were initiated. This development also related to central stakeholders' efforts to deal with the doping stigma in bodybuilding and fitness. The marginalisation of female bodybuilding and the boosting of disciplines 
such as Women's bikini-fitness have helped to make the connection between the modern gym and health paramount, and we will soon return to a discussion on how these processes have impacted upon the fitness doping demography of the 21st century. Before that we will, however, briefly address a recent development in bodybuilding that can be understood in relation to the culture's bad reputation, and a will to reattach bodybuilding to the development of a more general fitness trend.

\section{Natural Bodies and Bodybuilding}

The face of the gym and fitness has changed, and it is possible to talk about a globalised fitness revolution. One fascinating part of this history is, as has been touched upon, the strained but also independent relationship that has developed between bodybuilding and fitness. Whereas bodybuilding has often come to be associated with things such as steroids, vanity, hyper-masculinity, and violence, fitness has come to be constructed in alliance with values such as health, youth and beauty. Efforts to deal with the 'black-sheep' stigma and bad reputation of bodybuilding have also led to the development of natural bodybuilding.

Natural, that is drug-free, bodybuilding has developed rapidly over the last decades. This has become a distinct culture, with competitions, events, promoters and federations. The emergence of a broader movement towards natural bodybuilding can be located to the late 1980s and early 1990s (Liokaftos 2018). This development coincides with stricter regulation of anabolic steroids in the US. According to Liokaftos, the movement towards natural bodybuilding is also connected to a number of premature deaths of well-known bodybuilders, such as Mohammed Benaziza and Andreas Munzer. Their deaths were directly connected to substance use in connection with competitions. In the 1990s there was a growing social movement within bodybuilding, promoting natural bodybuilding. This movement was made visible through new bodybuilding media and also through the development of new organisations and organised sporting activities.

Supporters of natural bodybuilding make use of two discourses (Liokaftos 2018). The first one is about choice. Athletes should have the possibility to practice and compete in the sport without feeling the need and the pressure of using drugs. The second discourse is focused on values and the ethos of bodybuilding. Leaning on values, such as health, character-building and fair competitions, natural bodybuilding is trying to establish an alternative to PIED use. This movement is also interconnected to more general developments of anti-doping and anti-drug organisations in society. From the 2000s and onwards it is possible to identify a consolidation and global expansion of natural bodybuilding.

In the fourth phase of the historical development of fitness doping, strong efforts are made to 'clean up' gym and fitness culture. Health and fitness are constructed as paramount ideals and premises for weightlifting become fitness palaces for a diverse demographic of training enthusiasts. Bodybuilding remains and continues to bring new ideas about training and how to form bodies through diets, hard work and PIEDs. At the same time bodybuilding is largely marginalised in this new culture of fitness and firm bodies. Although natural bodybuilding shares many of the visions of bodybuilding in general—rationalisation, masculinity, productivity and the self as a project-it is also an alternative to individuals becoming involved in the riskier and more extreme and (thought to be) deviant milieus of bodybuilding. It is, of course, also possible to discern a dynamic relation between, on the one hand, extreme bodybuilding — where drugs and PIEDs are inherent parts of the 'sport' —and natural bodybuilding. The latter offers a way out of the subcultural and drug-saturated environments and competitions. Natural bodybuilding is also more on terms with the general development of fitness culture in society, and a mainstreaming of the sport.

\section{A Globalised (and Virtual) Drug Market-Entering a Fifth Phase?}

The use of PIEDs has increased, internationally, since the late 1970s and onwards (Bates and McVeigh 2016; Antonopoulos and Hall 2016). Previously seen more or less exclusively as a problem within elite sport, the use of doping and the doping market has 'spread' to gym culture, to male bodybuilders, then female bodybuilders, non-elite athletes and more recently among what are 
perceived to be regular gym goers and fitness enthusiasts (McVeigh et al. 2015; Hanley Santos and Coomber 2017). The profile and market for potential users has seemingly diversified, and so has the literature on motivations for and experiences of PIED use (see, for example, Christiansen et al. 2016; Christiansen 2018; Kimergård and McVeigh 2014; Sagoe et al. 2015). Not surprisingly, in line with processes of globalisation of gym and fitness culture and an increasing diversification of the fitness doping demography, the supply and range of available (illicit and licit) PIEDs has also widened (Coomber et al. 2015; Fincoeur et al. 2015; Van Hout and Kean 2015). This development has further been fuelled by the possibility to use the Internet for discussing, learning about and dealing with PIEDs. As suggested by Van de Ven and Mulrooney (2017), however, scholars have mainly focused on how to understand users' perspectives on consumption, and thus to some extent neglecting methods and models for understanding the supply side of the drug market.

The market and distribution of fitness doping follows a roughly similar route as the development of gym and fitness culture. In the 1980s and 1990s the doping market was often described as following a social, and less commercially-driven, model (Van de Ven and Mulrooney 2017). Here, dealing networks were mainly constituted in such ways that there were well-developed relationships between sellers and buyers. Put differently; experienced users/bodybuilders often 'helped out' and supported new friends at the gym, not only by supplying the drugs but also by mentoring them on how to use PIEDs (Andreasson and Johansson 2016; Monaghan 2001, 2012). To this end, the doping market was somewhat embedded in the local and cultural spatiality of the gym.

Since the turn of this century, however, and as a consequence of stricter anti-doping policies and regulations, this has changed. Inherent risks of encounters with the police, in some countries, have diminished the level of sociability among fitness doping suppliers. Instead there is a growing market of online communities and opportunities through which socioculturally embedded suppliers are being replaced by profit-driven dealers (Fincoeur et al. 2015). Evolving since the turn of this century is thus a new type of (online) market, with commercially-motivated suppliers (Van de Ven and Mulrooney 2017). Fully in line with neoliberal values we thus have a process of globalisation, through which the doping market is gradually being relocated from being socioculturally embedded to being disembedded and commercial in an international and most often virtual and anonymous arena. Needless to say, this displacement not only poses a great challenge for national anti-doping policies and law enforcement, it also runs the risk of increasing drug use and loss of social support and mentoring of the use.

\section{Conclusions}

The first phase of the history of contemporary fitness doping derives from a pre-history of bodybuilding and can be connected to physical culture, and strongmen of the early 20th century. This period of time was in many ways formative for the development of gym culture and bodybuilding, not least concerning the training techniques used to mould the bodies of men. Yet, this formative phase is only but a starting point. The development within bodybuilding from the 1970s and onwards - the establishment of IFBB, the stardom of Arnold Schwarzenegger and others, the rise of female bodybuilding, and the mediatisation of bodybuilding and fitness can be interpreted as elements of a second phase of the development of gym and fitness culture. In contrast to the pre-historical development, we can also identify a development towards a global culture, accentuated by the mediatisation of society, and the development of a global business enterprise. Whereas the discussion on PIEDs in the 1960s and 70s, within sports in general, led to legislation and gradually more-developed control systems, bodybuilding seemed to have created a secluded space for improving and using steroids and other substances. However, gradually the optimism and celebration of drugs in the second phase, turned into a crisis and to a more critical approach to bodybuilding in general and to health risks associated with drug-using practices in particular. During the late 1980s and 90s bodybuilding and the associated lifestyle became questioned in public discourse, which in this text has been described as a third phase, and in order to preserve and develop gym and fitness culture, strong attempts were made to dissociate fitness culture from bodybuilding and especially from the use of illicit substances. This 
can be interpreted as a form of 'civilising process' - adapting gym culture to a more accepted form of drug-free fitness culture-where the whole gym and fitness culture gradually changed appearance and became something quite new and different from the subcultural forms of bodybuilding we saw in the 1970s in the United States, Sweden and other countries (Elias and Dunning 1986). In this fourth phase, which has been addressed as the fitness revolution, gym culture transformed into a fitness enterprise in which drug-using practices as well as bodybuilding were, to a certain extent, exiled.

What we see today is, however, perhaps, the initiation of a fifth phase in this historical development. Increasingly, we have discussions on the effectiveness of the control systems created, and also on how to develop more holistic approaches to drug use in sports (Vidar Hanstad and Waddington 2009; Waddington and Smith 2009). There are also critical discussions on the stigmatisation of, for example, human growth hormones (HGH). López (2012) for example argues that there is a lack of evidence for the deleterious and fatal side-effects of HGH. Furthermore, López argues that the alarming reports of the health dangers associated with HGH were highly publicised and, subsequently, became standardised by the media. Through repetition and a lack of confrontation with critical investigations, HGH has become defined as detrimental to athletes' health. Critics of the anti-doping position are gradually gaining ground. Gleaves (2010) argues that there is a possibility that harm-free PIEDs may be manufactured in the future. This development can of course also be situated in relation to what Conrad (2007) describes as the medicalization of society, which is a societal process characterized by a rationality, common within modern medicine, according to which pharmaceuticals provide quick and easy solutions to a variety of physical problems, and as such benefitting from them is logical (see also Pedersen 2010). In order to continue the anti-doping work, there will probably be a need to elaborate other types of arguments and values, more connected to the intrinsic values of sport and ethical ideas of natural bodybuilding, for example.

Author Contributions: J.A. has been responsible for the study. All the different steps in the research process has however been carried out in close and dialogical collaboration with T.J. The paper is written by both authors.

Funding: This research was funded by the Swedish Research Council for Health, Working Life and Welfare (FORTE) grant number 2017-01572.

Conflicts of Interest: The authors declare no conflict of interest.

\section{References}

Al-Falasi, Omar, Khalid Al-Dahmani, Khalid Al-Eisaei, Salem Al-Ameri, Fatma Al-Maskari, Nicholas Nagelkerke, and John Schneider. 2008. Knowledge, attitude and practice of anabolic steroids use among gym users in Al-Ain District, United Arab Emirates. The Open Sports Medicine Journal 9: 75-81. [CrossRef]

Allahverdipour, Hamid, Farzad Jalilian, and Abdolreza Shaghaghi. 2012. Vulnerability and the intention to anabolic steroids use among Iranian gym users: An application of the theory of planned behavior. Substance Use E Misuse 47: 309-12.

Andreasson, Jesper, and Thomas Johansson. 2014. The Global Gym. Gender, Health and Pedagogies. Basingstoke: Palgrave Macmillan.

Andreasson, Jesper, and Thomas Johansson. 2016. Online doping: The new self-help culture of ethnopharmacology. Sport in Society: Cultures, Media, Politics, Commerce 19: 957-72. [CrossRef]

Antonopoulos, Georgios A., and Alexandra Hall. 2016. 'Gain with no pain': Anabolic-androgenic steroids trafficking in the UK. European Journal of Criminology 13: 696-713. [CrossRef]

Baker, Sarah, Bob Buttigieg, and Brady Robards. 2015. Youth Cultures and Subcultures. Australian Perspectives. Farnham: Ashgate Publisher.

Bates, Geoff, and Jim McVeigh. 2016. Image and Performance Enhancing Drugs: 2015 Survey Results. Liverpool: Liverpool John Moores University.

Budd, Michael Anton. 1997. The Sculpture Machine. Physical Culture and Body Politics in the Age of Empire. London: MacMillan Press.

Bunsell, Tanya. 2013. Strong and Hard Women. An Ethnography of Female Bodybuilding. London: Routledge.

Butler, Judith. 1990. Gender Trouble. Feminism and the Subversion of Identity. London: Routledge. 
Butler, Judith. 1993. Bodies That Matter. On the Discursive Limits of "Sex". London: Routledge.

Christiansen, Ask Vest. 2018. Motionsdoping. Styrketræning, Identitet og Kultur [Recreational Doping. Strength Training, Identity and Culture]. Aarhus: Aarhus Universitetsforlag.

Christiansen, Ask Vest, Anders Schmidt Vinther, and Dimitris Liokaftos. 2016. Outline of a typology of men's use of anabolic androgenic steroids in fitness and strength training environments. Drugs: Education, Prevention and Policy 24: 295-305. [CrossRef]

Connell, Robert William. 1995. Masculinities. Cambridge: Polity Press.

Connolly, John. 2015. Civilising processes and doping in professional cycling. Current Sociology 63: 1037-57. [CrossRef]

Conrad, Peter. 2007. The Medicalization of Society. On the Transformation of Human Conditions into Treatable Disorders. Baltimore: The Johns Hopkins University Press.

Coomber, Ross, Adele Pavlidis, Gisella Hanley Santos, Michael Wilde, Wiebke Schmidt, and Clare Redshaw. 2015. The supply of steroids and other performance and image enhancing drugs (PIEDs) in one English city: Fakes, counterfeits, supplier trust, common beliefs and access. Performance Enhancement and Health 3: 135-44. [CrossRef]

Dimeo, Paul. 2006. Good versus evil? Drugs, sport and the Cold War. In East Plays West. Sport and the Cold War. London: Routledge.

Dimeo, Paul. 2007. A History of Drug Use in Sport 1876-1976. Beyond Good and Evil. London: Routledge.

Elias, Norbert, and Eric Dunning. 1986. Quest for Excitement: Sport and Leisure in the Civilizing Process. Oxford: Basil Blackwell.

Evans-Brown, Michael, Jim McVeigh, Clare Perkins, and Mark A. Bellis. 2012. Human Enhancement Drugs. The Emerging Challenges to Public Health. Liverpool: North West Public Health Observatory.

Fair, John D. 1999. Muscletown USA. Bob Hoffman and the Manly Culture of York Barbell. University Park: The Pennsylvania State University Press.

Fincoeur, Bertrand, Katinka Van de Ven, and Kyle J. D. Mulrooney. 2015. The symbiotic evolution of anti-doping and supply chains of doping substances: how criminal networks may benefit from anti-doping policy. Trends in Organized Crime 18: 229-50. [CrossRef]

Fussell, Sam. 1991. Muscle. In Confessions of an Unlikely Bodybuilder. London: Scribners.

Gaines, Charles, and George Butler. 1974. Pumping Iron. The Art and Sport of Bodybuilding. London: Sphere Books Ltd.

Gleaves, John. 2010. No harm, no foul? Justifying bans on safe performance-enhancing drugs. Sport, Ethics and Philosophy 4: 269-83. [CrossRef]

Gleaves, John, and Thomas Hunt. 2015. A Global History of Doping in Sport: Drugs, Policy, and Politics. London: Routledge.

Hanley Santos, Gisella, and Ross Coomber. 2017. The risk environment of anabolic-androgenic steroid users in the UK: Examining motivations, practices and accounts of use. International Journal of Drug Policy 40: $35-43$. [CrossRef]

Haraway, Donna. 1990. A Manifesto for Cyborgs. Science, Technology and Socialist feminism in the 1980s. In Feminism/Postmodernism. London: Routledge.

Hebdige, Dick. 1979. Subculture. The Meaning of Style. London: Routledge.

Hodkinson, Paul. 2002. Goth. Identity, Style and Subculture. Oxford: Berg.

Hoff, David. 2013. Dopning utanför idrotten-Individualisering och muskulösa skönhetsideal. En studie av dopning i grundskola, gymnasium och pågym i Kalmar kommun. Scandinavian Sport Studies Forum 4: 1-24.

Holt, Richard I. G., Ioulietta Erotokritou-Mulligan, and Peter H. Sönksen. 2009. The history of doping and growth hormone abuse in sport. Growth Hormone \& IGF Research 19: 320-26.

Hunt, Thomas M., Paul Dimeo, Florian Hemme, and Anne Mueller. 2014. The Health Risks of Doping during the Cold War: A Comparative Analysis of the Two Sides of the Iron Curtain. The International Journal of the History of Sport 31: 2230-44. [CrossRef]

IFBB. 2018. Our Disciplines. Available online: https:/ / ifbb.com/our-disciplines/ (accessed on 3 October 2018).

Johansson, Thomas, and Marcus Herz. 2019. Youth Studies in Transition. Culture, Generation and New Learning Processes. Basel: Springer Nature Switzerland.

Johansson, Thomas, Jesper Andreasson, and Christer Mattsson. 2017. From Subcultures to Common Culture: Bodybuilders, Skinheads, and the Normalization of the Marginal. Sage Open 7: 1-9. [CrossRef] 
Kimergård, Andreas. 2015. A qualitative study of anabolic steroid use amongst gym users in the United Kingdom: motives, beliefs and experiences. Journal of Substance Use 20: 288-94. [CrossRef]

Kimergård, Andreas, and Jim McVeigh. 2014. Variability and dilemmas in harm reduction for anabolic steroid users in the UK: A multi-area interview study. Harm Reduction Journal 11: 1-13. [CrossRef] [PubMed]

Klein, Alan M. 1993. Little Big Men. Bodybuilding, Subculture and Gender Construction. New York: State University of New York Press.

Kremenik, Michael, Sho Onodera, Mitsushiro Nagao, Osamu Yuzuki, and Shozo Yonetani. 2006. A Historical Timeline of Doping in the Olympics (Part 1 1896-1968). Kawasaki Journal of Medical Welfare 12: 19-28.

Lindsay, Cecile. 1996. Bodybuilding: A Postmodern Freak Show. In Freakery. Cultural Spectacles of the Extraordinary Body. New York: New York University Press.

Liokaftos, Dimitrios. 2018. Natural bodybuilding: An account of its emergence and development as competition sport. International Review for the Sociology of Sports, 1-18. [CrossRef]

Locks, Adam, and Niall Richardson. 2012. Critical Readings in Bodybuilding. London: Routledge.

López, Bernat. 2012. Creating fear: The social construction of Human Growth Hormone as a dangerous drug. International Review for the Sociology of Sports 48: 220-37.

Luciano, Lynne. 2001. Looking Good. Male Body Image in Modern America. New York: Hill and Wang.

McGrath, Shelly A., and Ruth A. Chananie-Hill. 2009. 'Big Freaky-Looking Women'. Normalizing Gender Transgression Through Bodybuilding. Sociology of Sport Journal 26: 235-54. [CrossRef]

McKenzie, Shelly. 2013. Getting Physical. The Rise of Fitness Culture in America. Lawrence: University Press of Kansas.

McVeigh, Jim, Geoff Bates, and Martin Chandler. 2015. Steroids and Image Enhancing Drugs 2014 Survey Results. Available online: http:/ /www.drugs.ie/resourcesfiles/ResearchDocs/Europe/Research/2015/Steroids_ and_Image_Enhancing_Drugs_2015.pdf (accessed on 1 March 2019).

Mogensen, Kevin. 2011. Body Punk. En Afhandling om Mandlige Kropsbyggere og Kroppens Betydninger $i$ Lyset av Antidoping Kampagner [Body Punk. A Thesis on Male Bodybuilders and the Meanings of the Body in the Light of Anti-Doping Campaigns]. Roskilde: Roskilde Universitetscenter.

Monaghan, Lee F. 2001. Bodybuilders Drugs and Risk. Health, Risk and Society. New York: Routledge.

Monaghan, Lee F. 2012. Accounting for Illicit Steroid Use. Bodybuilders' Justifications. In Critical Readings in Bodybuilding. New York: Routledge.

Pedersen, Inge Kryger. 2010. Doping and the perfect body expert: Social and cultural indicators of performance-enhancing drug use in Danish gyms. Sport in Society 13: 503-16. [CrossRef]

Pineau, Thomas, Adrien Schopfer, Lionel Grossrieder, Julian Broséus, Pierre Esseiva, and Quentin Rossy. 2016. The study of doping market: How to produce intelligence from Internet forums. Forensic Science International 268: 103-15. [CrossRef]

Pope, Harrison G., Gen Kanayama, Alison Athey, Erin Ryan, James I. Hudson, and Aaron Baggish. 2014. The lifetime prevalence of anabolic-androgenic steroid use and dependence in Americans: Current best estimates. The American Journal on Addictions 23: 371-77. [CrossRef] [PubMed]

Richardson, Niall. 2008. Flex-rated! Female bodybuilding: feminist resistance or erotic spectacle? Journal of Gender Studies 17: 289-301. [CrossRef]

Rosen, Daniel M. 2008. A History of performance Enhancement in Sports from the Nineteenth Century to Today. Westport: Praeger.

Roussel, Peggy, Lee F. Monaghan, Sophie Javerlhiac, and François Le Yondre. 2010. The metamorphosis of female Bodybuilders: Judging a paroxysmal body? International Review for the Sociology of Sport 45: 103-9. [CrossRef]

Sagoe, Dominic, Jim McVeigh, Astrid Bjørnebekk, Marie-Stella Essilfie, Cecilie Schou Andreassen, and Ståle Pallesen. 2015. Polypharmacy among anabolic-androgenic steroid users: A descriptive metasynthesis. Substance Abuse: Treatment, Prevention, and Policy 10: 1-19. [CrossRef] [PubMed]

Santos, Azenildo Moura, Manoel Sérgio Pereira da Rocha, and Marcos Freire da Silva. 2011. Illicit use and abuse of anabolic-androgenic steroids among Brazilian bodybuilders. Substance Use E Misuse 46: 742-48.

Sassatelli, Roberta. 2010. Fitness Culture. Gyms and the Commercialisation of Discipline and Fun. Hampshire: Palgrave Macmillan.

Schwarzenegger, Arnold, and Peter Petre. 2012. Total Recall: My Unbeliveably True Life Story. New York: Simon \& Schuster, Inc.

Smith Maguire, Jennifer. 2008. Fit for Consumption. Sociology and the Business of Fitness. London: Routledge. 
Van de Ven, Katinka, and Kyle J. D. Mulrooney. 2017. Social suppliers: Exploring the cultural contours of the performance and image enhancing drug (PIED) market among bodybuilders in the Netherlands and Belgium. International Journal of Drug Policy 40: 6-15. [CrossRef] [PubMed]

Van Hout, Marie Claire, and Joseph Kean. 2015. An exploratory study of image and performance enhancement drug use in a male British South Asian community. International Journal of Drug Policy 26: 860-67. [CrossRef]

Verroken, Michele. 2006. Drug use and abuse in sport. In Drugs in Sport, 4th ed. London: Routledge, pp. 29-63.

Vertinsky, Patricia. 1999. Making and marking gender: Bodybuilding and the medicalization of the body from one century's end to another. Culture, Sport, Society 2: 1-24. [CrossRef]

Vidar Hanstad, Dag, and Ivan Waddington. 2009. Sport, health and drugs: A critical re-examination of some key issues and problems. Perspectives in Public Health 129: 174-82. [CrossRef]

Waddington, Ivan, and Andy Smith. 2009. An Introduction to Drugs in Sport. Addicted to Winning? New York: Routledge.

Wesely, Jennifer K. 2001. Negotiating gender: Bodybuilding and the natural/unnatural continuum. Sociology of Sport Journal 18: 162-80. [CrossRef]

Yesalis, Charles E., and Michael S. Bahrke. 2007. Anabolic steroid and stimulant use in North American sport between 1850 and 1980. In Drugs, Alcohol and Sport. New York: Routledge.

(C) 2019 by the authors. Licensee MDPI, Basel, Switzerland. This article is an open access article distributed under the terms and conditions of the Creative Commons Attribution (CC BY) license (http:/ / creativecommons.org/licenses/by/4.0/). 